\title{
Peculiar optical properties of modified surface of monocrystalline cadmium telluride
}

\author{
Makhniy V.P., Slyotov M.M. and Skrypnyk N.V. \\ Chernivtsi Yuriy Fedkovych National University, 2 Kotsubynsky St., 58012 \\ Chernivtsi, Ukraine, e-mail: Skrup@meta.ua
}

Received: 09.01.2009

\begin{abstract}
Optical characteristics of single-crystalline CdTe wafers are investigated. Their thermal annealing in the air brings about a wide luminescence band in the region of fundamental absorption $\left(\hbar \omega>E_{g}\right)$, increase in the optical transmission factor $T_{\omega}$ by more than one order of magnitude, as well as a shift of the high-energy edge $T_{\omega}$ curve to $1.3 \mathrm{eV}$. These peculiarities are adequately explained in the framework of theory of quantum-size effects.
\end{abstract}

Keywords: cadmium telluride, nanostructure, modification, photoluminescence, optical spectra.

PACS: 78.55.Et

UDC: 535.37

\section{Introduction}

Investigations of quantum-size effects in semiconductors are both scientifically and practically interesting and open up ways for creating materials and devices with basically new properties. A particular place is occupied by surface nanostructures produced with different techniques (molecular-beam epitaxy, MOS-hybrid technology, gas phase deposition, chemical wetting, laser ablation and deposition, etc. [1-3]). In spite of considerable number of technologies, the majority of them are rather complicated and costly. Therefore searches for simpler methods for creating nanoobjects are being continued. One of them can be modification of surfaces of semiconductor substrates, e.g. produced by thermal annealing of the latter in the air. In particular, this method has been used to obtain nanostructured surface of monocrystalline wafers for a number of wide-gap II-VI compounds [4]. Unlike the non-annealed samples, luminescence spectra of the samples with modified surfaces manifest a broad band, with its maximum located at the energy exceeding considerably the energy gap for a given material. Moreover, the modification also causes essential increase in the efficiency of edge emission, testifying to a reduced rate of surface recombination [5]. Note that it is precisely the use of such substrates in manufacturing of $\mathrm{Au}-\mathrm{CdTe}$ diodes that has already enabled raising the efficiency of photo-transformation up to $13 \%$ at $300 \mathrm{~K}$ under AM2 illumination conditions [6]. In the present paper we report on revealing a number of other peculiarities of optical properties of the modified CdTe surface layers. 


\section{Objects and methods of investigation}

Wafers with the dimensions $4 \times 4 \times 1 \mathrm{~mm}^{3}$ cut from a bulk CdTe crystal were used as basic substrates. The latter was grown using the Bridgman method. At $300 \mathrm{~K}$ the intrinsic conductivity of the crystal is of electron type $\left(0.05-0.1 \mathrm{Ohm}^{-1} \mathrm{~cm}^{-1}\right)$, as no other impurities were used as dopants during the growing process. The substrates were subjected to consecutive steps of mechanical grinding, polishing and chemical etching in $\mathrm{K}_{2} \mathrm{Cr}_{2} \mathrm{O}_{7}: \mathrm{H}_{2} \mathrm{O}: \mathrm{HNO}_{3}=4: 20: 10$ solution, as well as final washing in deionised water. As a result, the surface was visually perceived as smooth and a weak luminescence was observed on the samples at $300 \mathrm{~K}$. Note that a similar emission was also inherent in cleaved surfaces though it was absent in mechanically polished wafers.

As mentioned above, modification of the surface was performed by isothermal annealing in the air $[6,7]$. Our studies showed that there are optimal annealing parameters (the temperature $\mathrm{T}_{\alpha}$ and the time $\mathrm{t}_{\alpha}$ ) ensuring a maximum intensity of the edge band luminescence could be achieved. Surface topogram analysis of the substrates obtained by means of atomic-force microscope (AFM) of Nanoscope-III type indicated that just for these samples the surface was characterised by a granular structure with the lateral dimensions of grains $10-50 \mathrm{~nm}$, which could be combined into larger $(100-500 \mathrm{~nm})$ substrates (see Fig. 1). Each of these groups contributes to optical properties of the modified surface as will be explained below.

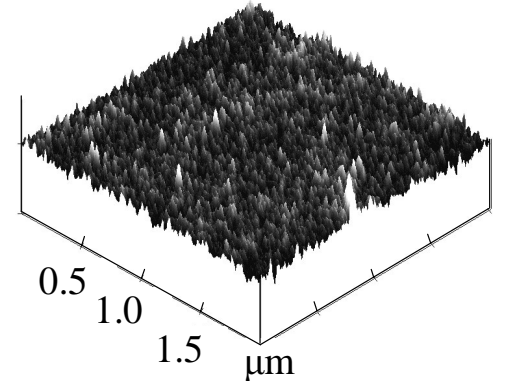

(a)

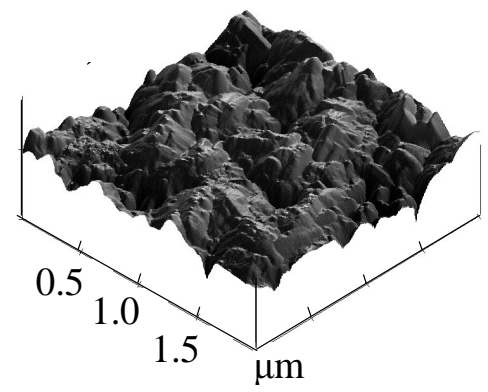

(b)

Fig. 1. AFM-topograms for the basic n-CdTe substrates (a) and the substrates annealed in the air at $500^{\circ} \mathrm{C}(\mathrm{b})$.

To excite luminescence radiation, $\mathrm{He}-\mathrm{Ne}$ and $\mathrm{N}_{2}$ lasers with the wavelengths of 0.63 and $0.337 \mu \mathrm{m}$, respectively, were used. Since the effective length of absorption of the excitation emission in cadmium telluride amounts to $1_{\rho} \leq 10^{-5} \mathrm{~cm}$, the photoluminescence is generated practically in the near-surface region. In this respect, the luminescence intensity $I$ in the first approximation may be considered as inversely proportional to the concentration of surface defects $N_{S}$. Samples annealed under optimal conditions were selected for further investigations, since they revealed minimal $N_{S}$ and maximal $I$ parameter. The spectra of emission $\left(N_{\omega}\right)$, reflectance $\left(R_{\omega}\right)$ and transmission $\left(T_{\omega}\right)$ were studied with a general-purpose apparatus that enabled performing the measuring process in both conventional and differential modes [8]. The spectra were recorded automatically with the aid of 
KSP-2 plotter that allowed also recording the relaxation curves of photoluminescence intensity. When measuring the reflectance and transmission spectra, xenon lamp with a "smooth" spectrum in the spectral range under study was used as a light source. All the optical spectra were corrected with regard to measuring path nonlinearities. The photoluminescence spectra were plotted in the following coordinates: number of photons in the unit energy interval $N_{\omega}$ versus the photon energy $\hbar \omega$.

\section{Results and discussion}

The salient feature of luminescence of the annealed samples is appearance in its spectra of a wide emission band lying in the region of intrinsic absorption of CdTe (i.e., at $\hbar \omega>E_{\mathrm{g}}-$ see Fig. 2). The halfwidth $\Delta \hbar \omega_{1 / 2}$ of this band referred hereafter as $B$-band is within $0.7-0.8 \mathrm{eV}$ at $300 \mathrm{~K}$. It has been established that the intensity of the high-energy $B$-band is reduced in the course of time, while its maximum $\hbar \omega_{m}$ is slightly shifted towards low-energy region. The steady-state $I$ and $\hbar \omega_{m}$ values are reached several minutes after laser excitation is switched on (Fig. 3), and so the photoluminescence spectrum (see curve 1 in Fig. 2) has been measured just under these conditions. Note also that the intensity of the $B$-band and the time $t_{1 / 2}$ needed for reaching its half-value reduce with increasing temperature. Therefore the experimental dependence of $t_{1 / 2}$ on the temperature $T$ is adequately described with the well-known Arrhenius law (see insert in Fig. 3), the activation energy being equal to $\sim 0.2 \mathrm{eV}$.

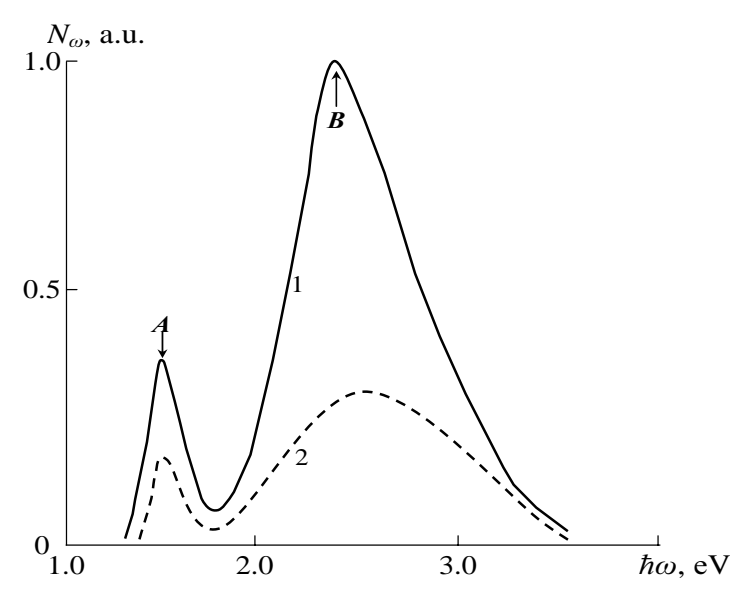

Fig. 2. Luminescence spectra for $\mathrm{CdTe}: \mathrm{O}_{2}$ substrates with the free surface (curve 1) and the gold films (curve 2) at $300 \mathrm{~K}$.

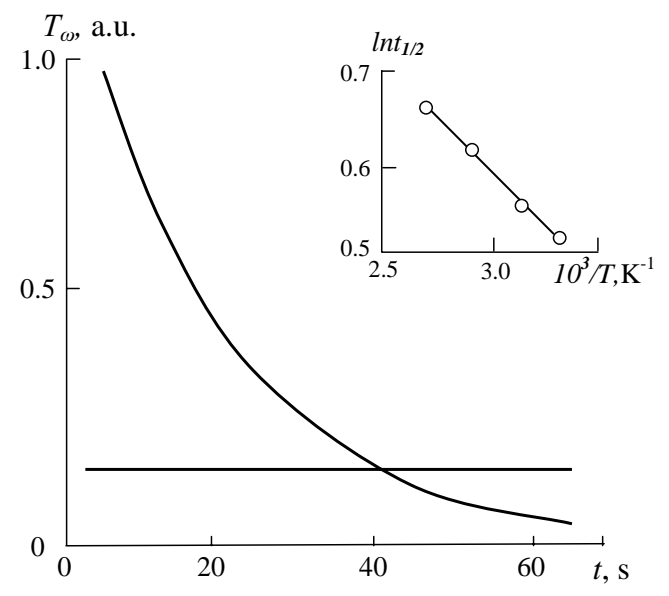

Fig. 3. Temporal dependence of the Bband intensity at $300 \mathrm{~K}$. The insert shows temperature dependence of the time $t_{1 / 2}$.

As seen from Fig. 2, the photoluminescence spectrum has also a narrower A-band with its maximum located around $1.5 \mathrm{eV}$, which is associated with band-to-band recombination in the basic CdTe. As for the high-energy $B$-band, its presence might be attributed to a size quantization of charge carrier energy as a result of formation of nanostruc- 
ture. The change in the transition energy due to the size quantization may be represented as [9]

$$
\Delta E=\frac{\pi^{2} \hbar^{2}}{2 d^{2}}\left(\frac{1}{m_{n}^{*}}+\frac{1}{m_{p}^{*}}\right),
$$

where $m_{n}{ }^{*}$ and $m_{p}{ }^{*}$ are the effective masses of electron and hole, respectively, and $d$ denotes the size of nanoobjects, of which radiation defines the energy $\hbar \omega_{m}$ in the photoluminescence spectrum. The depth of the quantum well for such objects is as follows:

$$
\Delta E=\hbar \omega_{m}-E_{g} .
$$

After substituting the well-known parameters $m_{n}{ }^{*}=0.11 m_{0}, m_{p}{ }^{*}=0.35 m_{0}\left(m_{0}\right.$ being the electron mass), $E_{g}=1.5 \mathrm{eV}$ [10] and the experimental value $\hbar \omega_{m} \approx 2.5 \mathrm{eV}$ into Eqs. (1) and (2) one can estimate the $d$ value. It has turned out to be equal to $\sim 5 \mathrm{~nm}$, which is half the minimum lateral size of the fine grains $(d \approx 10 \mathrm{~nm})$ determined from the AFMtopograms. The discrepancy may be removed when considering that overwhelming majority of the grains are pyramid-shaped (see Fig. 1) and the B-band is formed by their apexes. This is indirectly confirmed as the photons with the energies $\hbar \omega>\hbar \omega_{m}$ are present in the spectrum, which can be due to nanoobjects with the $d$ sizes even less than $5 \mathrm{~nm}$.

It should also be noticed that the $B$-band cannot be caused by the luminescence of $\mathrm{CdO}$ film, the appearance of which is, in principle, not excluded as a result of our annealing procedure. This is proved by a series of experimental facts. First of all, it is the absence of visible emission in the spectra of samples with $\mathrm{CdO}$ film specially grown with photo-thermal oxidation technique on the CdTe substrates with smooth surfaces [11]. Secondly, the differential reflectance spectrum of these samples has a peak corresponding to $E_{g}$ for the cadmium oxide though this peak is absent in the similar spectra of basic and modified substrates (see Fig. 4). Therefore the peak at $1.5 \mathrm{eV}$ corresponds to the energy distance between the bottom of conductance band $E_{c}$ and the edge of basic valence subband $E_{v a}$, whereas the peak at $2.4 \mathrm{eV}$ refers to the distance between the bottom of conductance band and the edge of valence subband $E_{v c}$ split due to spin-orbital splitting $\Delta_{S O}$ (see insert in Fig. 4). The peak with $\hbar \omega_{m} \approx 2.6 \mathrm{eV}$ correlates with the energy gap for the cadmium oxide at $300 \mathrm{~K}$ [10]. Finally, let us emphasise that the high-energy "wing" of the $B$ band is shifted much farther than it is required issuing from the $E_{g}$ value for the cadmium oxide.

Another peculiarity of the samples with the modified surface is a drastic growth of the efficiency $\eta$ that can reach several per cent for the $A$-band. At the same time, this parameter does not exceed $0.01 \%$ for the substrates with the smooth surface. This confirms essential reduction of the surface recombination rate in the modified CdTe substrates, which may serve a basis for efficient photo- and light-emitting diodes, including those for the short-wavelength region. In order to implement this idea in practice, it is first of all necessary to solve the problem of time instability of the photoluminescence intensity typical of the modified substrates. Our investigations have shown that deposing of half- 
transparent gold film on the surface of such samples leads to stabilization of the $I$ value with time, as illustrated in Fig. 3. We are to stress that, though the figure shows only the initial fragment of $I(t)$ dependence, it remains unvaried not only for several hours, but also after a series of laser excitation switchings on and off. The result obtained is of a crucial importance from the practical standpoint, since it is just the half-transparent gold film that serves as a rectifying contact in efficient photocells based on the modified CdTe substrates [6].
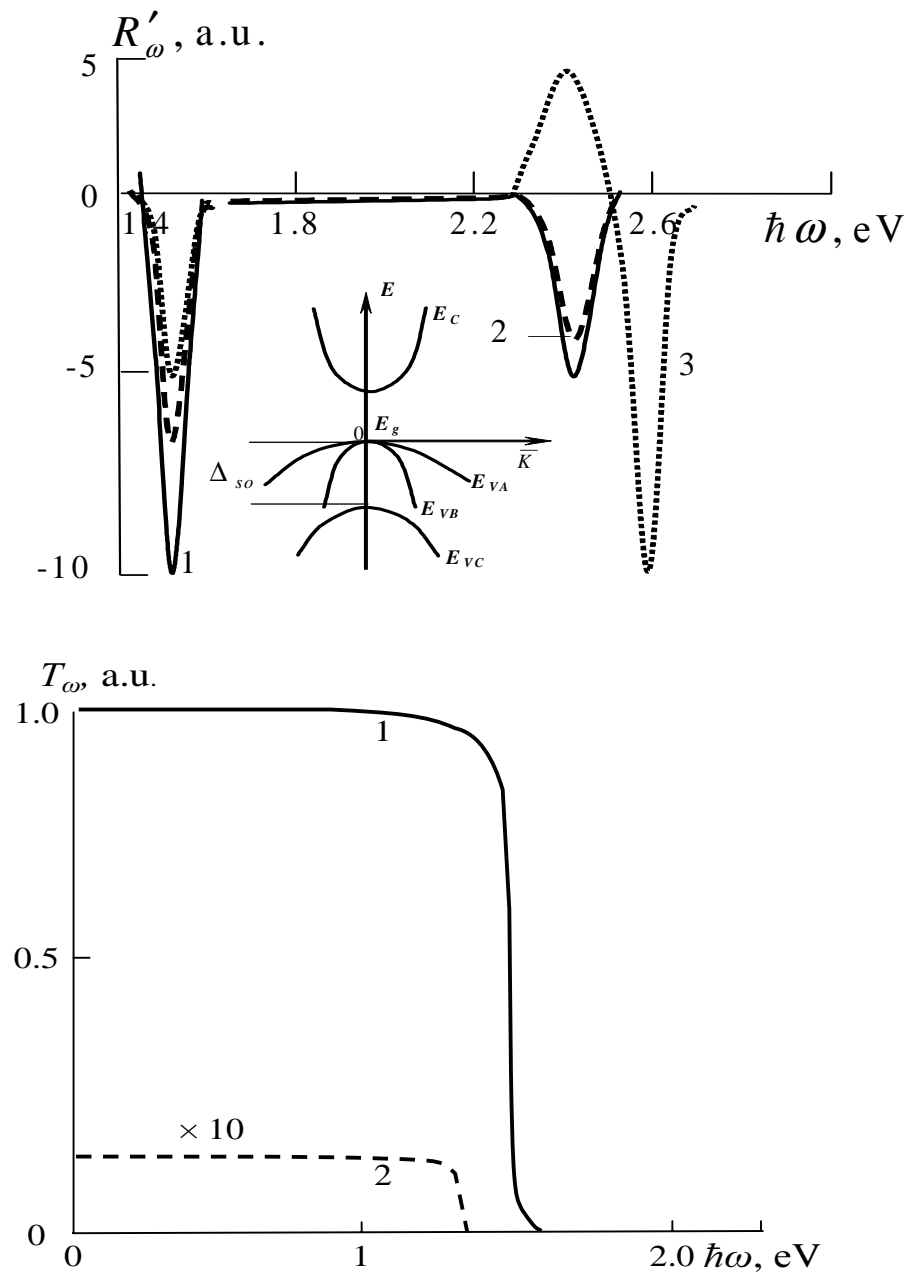

Fig. 4. Differential reflectance spectra for $\mathrm{n}$-CdTe (curve 1) and $\mathrm{n}-\mathrm{CdTe}: \mathrm{O}_{2}$ (curve 2) substrates and for $\mathrm{CdO} / \mathrm{CdTe}$ heterostructure (curve 3) at $300 \mathrm{~K}$.

Fig. 5. Optical reflectance spectra for CdTe (curve 1) and $\mathrm{CdTe}: \mathrm{O}_{2}$ (curve 2) substrates at $300 \mathrm{~K}$.

In conclusion, let us consider the effect of surface modification for the monocrystalline cadmium telluride on the optical transmission. As evident from Fig. 5, this modification causes not only essential reduction of the $T_{\omega}$ value, but also displacement of the highenergy transmission edges towards lower energies. The cutoff of the abscissa axis gives the energy $\hbar \omega \approx 1.3 \mathrm{eV}$, which is essentially less than the value $1.5 \mathrm{eV}$ expected for the cadmium telluride $E_{g}$ at $300 \mathrm{~K}$ (see curve 1 in Fig. 5). The peculiarities of the transmission revealed by us are owing to presence on the modified surface of subgrains with the lateral dimensions of the order of $100-500 \mathrm{~nm}$. They can induce the processes of light 
scattering and multiple reflections, thus leading to decrease in the $T_{\omega}$ magnitude. Since the latter processes become more critical with increasing $\hbar \omega$, they bring about a shift of the $T_{\omega}$ curve towards the high-frequency region. Notice that a similar effect has also been observed in the photosensitivity spectra $S_{\omega}$ for $\mathrm{Au}-\mathrm{CdTe}$ contacts made upon modified substrates. It has manifested itself in essential $S_{\omega}$ increase at $\hbar \omega<E_{g}$ for the cadmium telluride [6].

\section{Conclusions}

Thus, the peculiarities of optical characteristics of the cadmium telluride substrates with the modified surfaces revealed in this work could be adequately explained in the framework of current concepts of quantum-size effects. The presence of surface nanostructure is experimentally confirmed by the AFM-topograms. Formation of the structure is most probably caused by self-organization processes [11] that are quite plausible with regard to narrow temperature and time intervals of annealing [7]. Besides, maintaining the same values of the parameters under other conditions (e.g., inert atmosphere or vacuum) does not activate the desired effect, thus testifying to some role of atmosphere ingredients in the formation of nanocrystalline structure. A final answer concerning these selforganization processes may be provided only via further experimental and theoretical studies which are beyond the scope of this work.

\section{References}

1. Zayachuk D M, Low-dimensional structures and superlattices. Lviv: Lvivska Politekhnika, (2006).

2. Pool Ch P Jr, Owens F J, Introduction to Nanotechnology, New Jersey: WileyInterscience, (2003).

3. Nevolin V K, Scanning-Probe Technologies in Electronics, Moscow: Tekhnosfera, (2005).

4. Makhniy V P, Sletov M M, Mel'nyk V V, Grivul V I, Horley P P, Gorley P M, Horvath Zs J, Luminescence peculiarities of wide-gap II-VI compounds with quantum-size surface structure. Proceedings of First International Workshop on Semiconductor Nanocrystals, SEMINANO2005, September 10-12, 2005 Budapest, Hungary. 287-289.

5. Makhniy V P, Demich M V, Slyotov M M, 2003. Method the treatment of crystals cadmium - zinc telluride. Decl. patent Ukraine №5010A.

6. Ciach R, Demich M V, Gorley P M, Kuznicki Z, Makhniy V P, Malimon I V, Swiatek Z,1999. Photo and X-ray sensitive heterostructures based on cadmium telluride. J. Cryst. Growth. 197: 675-679.

7. Makhniy V P, 2007. Effects of thermal annealing on the physical properties surface layers monocrystalline cadmium telluride. Poverkhnost'. Rentgenovskie, Sinkhrotronnye i Neitronnye Issledovaniya, 1: $108-112$

8. Makhniy V P, Slyotov M M, Stets E V, Tkachenko I V, Gorley V V, Horley P P, 
2004. Application of modulation spectroscopy for determination of recombination center parameters. Thin Solid Films. 450: 222-225.

9. Savchuk A Yo, Semiconductors quantum structure. Chernivtsi: Ruta. (2006).

10. Grigoriev I S and Meilikhov E Z Ed., Physical values. Reference book, Moscow: Energoatomisdat, (1991).

11. Nykolys G, Prygozyn I, Self - organization in nonequal systems. Moscow: Mir, (1979).

Анотація. Досліджені оптичні властивості монокристалічних підкладок СdТе. Показано, щзо їх температурний відпал в атмосфері повітря приводить до виникнення иирокої смуги люмінесиениії в області фундаментального поглинання $\left(\hbar \omega>E_{g}\right)$, до зростання оптичного пропускання $T_{\omega}$ більш ніж на порядок, а також до зміщення кривої високо-енергетичного краю $T_{\omega}$ до 1,3 еВ. Ці особливості пояснюються в рамках теорї квантово-розмірних ефектів. 